\title{
Durable results of preserved valve and root after acute type A aortic dissection surgery in bicuspid aortic valve
}

\author{
Tsu-Jui Hsu ${ }^{1}$, Cheng-Wei Chen², and Ron-Bin $\mathrm{Hsu}^{2}$ \\ ${ }^{1}$ National Taiwan University Hospital Yun Lin Branch \\ ${ }^{2}$ National Taiwan University Hospital
}

January 3, 2022

\begin{abstract}
Background and aims of the study. Data on emergency surgery for acute type A aortic dissection in patients with bicuspid aortic valve were limited. Long-term results on the fate of the preserved bicuspid valve and aortic root were even rare. We sought to assess the clinical outcome of emergency acute type A aortic dissection surgery in patients with bicuspid aortic valve. Methods. From 2004 to 2021, 121 patients underwent emergency surgery for acute type A aortic dissection using a conservative aortic resection. Hospital and late outcomes were assessed in patients with bicuspid aortic valve. Results. Eight patients (6.6\%) had bicuspid aortic valve with 6 males (75\%) and median age of 49.5 years (range, 34 to 71). Four (50\%) had significant aortic valve dysfunction. Operation included ascending aortic grafting with aortic valve preservation in 4, ascending aortic grafting with aortic valve replacement in 3 and ascending aortic grafting with Bentall root replacement in 1 . Hospital mortality rate was $12.5 \%$ (1/8). With a median follow-up of 14.4 years, there was one late death and no proximal reoperation of 6 preserved roots and 3 preserved valves. Median diameter of preserved aortic roots changed from 42 (range, 33-43) to $38.5 \mathrm{~mm}$ (range, 35-46) with the average time of 11 years after surgery. Conclusions. Acute type A aortic dissection in bicuspid aortic valve was not associated with worse outcome. Aortic valve replacement was often required. Simultaneous root replacement was not always necessary. Preservation of normally functioning bicuspid valve and non-dilated root showed durable long-term results.
\end{abstract}

\section{Hosted file}

DAA BAV - journal of cardiac surgery.doc available at https://authorea.com/users/453683/ articles/551455-durable-results-of-preserved-valve-and-root-after-acute-type-a-aorticdissection-surgery-in-bicuspid-aortic-valve 